\title{
Lipopolysaccharide Induced Oxidative Stress and DNA Damage in Bovine Mammary Epithelial Cells
}

\author{
Yawang Sun, Yongjiang Wu, Jingbo Chen, Zili Wang, Juncai Chen, You Yang \\ and Guozhong Dong* \\ College of Animal Science and Technology, Southwest University, No.1 Tiansheng Rd, \\ Beibei District 400716, Chongqing, China.
}

\begin{abstract}
A B S T R A C T
This study investigated oxidative stress and the consequent DNA damage induced by lipopolysaccharide (LPS) in bovine mammary epithelial cell line MAC-T cells. Cells were cultured for $48 \mathrm{~h}$ with different LPS levels $(0,0.1,0.5,2.5,12.5$, and $100 \mathrm{ng} / \mathrm{mL})$. The results showed that cell viability was negatively correlated with LPS concentrations. The production of reactive oxygen species increased in a dosedepend manner. Cellular concentrations of oxidative damage markers were positively correlated with applied LPS concentrations. Total antioxidant capability and the activity of superoxide dismutase (SOD) increased with increasing LPS concentrations. Gene expression of antioxidants including SOD, NADPHquinone oxidoreductase 1 , and hemeoxygenase 1 were significantly increased at the LPS concentrations of 12.5 and $100 \mathrm{ng} / \mathrm{mL}$. Both Fanconi Anemia complementation group D2 protein and Fanconi Anemia complementation group L had significantly higher gene expression at $100 \mathrm{ng} / \mathrm{mL}$ LPS level. The protein expression of phosphorylated histone 2AX showed a linear rise in the range of LPS levels from 0 to 12.5 $\mathrm{ng} / \mathrm{mL}$, then significantly declined at $100 \mathrm{ng} / \mathrm{mL}$ LPS level. Oxidative stress and oxidative damage to protein and DNA were induced by LPS treatments, although the antioxidative defense was not impaired under LPS treatments. Upregulation of the Fanconi Anemia pathway mediated genes for activating cellular DNA repair pathway alleviated DNA damage at high LPS levels.
\end{abstract}

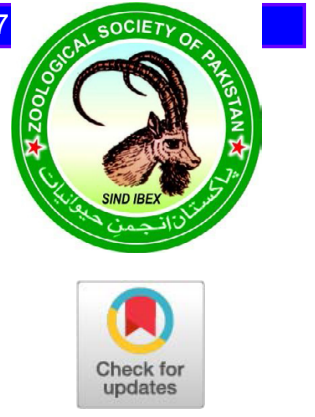

Article Information

Received 21 April 2020 Revised 03 June 2020

Accepted 20 June 2020

Available online 15 June 2021

Authors' Contribution

YS and GD conceived and designed the study. YS, YW and GD performed the experimental work. YS and JC validated the date. YS and ZW analyzed the date. YS, YY were involved in date curation. YS and GD prepared the original draft of the article. YS and YW helped in the preparation of the article. GD supervised the research work.

Key words

Lipopolysaccharide, Bovine,

Mammary epithelial cell, Oxidative

stress, DNA damage

\section{INTRODUCTION}

$\mathrm{L}$ ipopolysaccharide (LPS) is a component of gramnegative bacterial cell wall and it can elicit innate immune response through binding with the Toll-like receptor 4 (TLR4), resulting in activation of transcription factors, such as nuclear factor- $\kappa \mathrm{B}(\mathrm{NF}-\kappa \mathrm{B})$ (Iwasaki and Medzhitov, 2004). Subsequently, inflammatory mediators like interleukin (IL)-1 $\beta$, IL-6, IL-8 and tumor necrosis factor- $\alpha$ (TNF- $\alpha)$ were released in an increasing amount. The inflammatory mediators, especially TNF- $\alpha$, promote the production of reactive oxygen species (ROS) (Jin et al., 2016). Moreover, high level of LPS can directly stimulate the production of ROS in some immune cells including neutrophils and Kupffer cells (Abaker et al., 2017). Normally, ROS will be eliminated by the antioxidant defense system that can effectively scavenge ROS to maintain a dynamic equilibrium in organisms. However, over-production of ROS may result in oxidative stress (Sordillo and Aitken, 2009). The abundance of ROS under oxidative stress could damage major cellular

\footnotetext{
* Corresponding author: gzdong@swu.edu.cn 0030-9923/2021/0005-1631 \$9.00/0

Copyright 2021 Zoological Society of Pakistan
}

biomolecules, resulting in protein modification, lipid peroxidation and DNA damage (Dröge, 2002). DNA damage includes base pair loss, mismatch, deletion or insertion as well as single- or double-strand breaks and intra- and inter-strand cross-linkage. ROS primarily induces single or double strand breaks and nucleotide modifications (Altieri et al., 2008). Cellular DNA damage can result in cell cycle arrest, mutation and apoptosis, depending on the extent of the damage, which has implications in carcinogenesis, genetic disorders and aging (Shukla et al., 2010).

The primary function of mammary epithelial cells (MEC) is to synthesize milk protein, fat and other components. MEC can also serve as immune cells with the ability to bind LPS to initiate inflammation (Porcherie et al., 2012). In practical dairy production, the bovine MECs (bMECs) are frequently exposed to LPS. It has been a common practice in the dairy industry that dairy cows are fed high-concentrate diets to achieve high milk yield. However, high-concentrate diet feeding can lead to subacute ruminal acidosis (SARA), defined as a ruminal $\mathrm{pH}$ level of lower than 5.6 for more than 3 hours daily (Gressley et al., 2011). Decreased ruminal pH during SARA promotes the lysis of gram-negative bacteria, resulting in a large amount of LPS release in the rumen. 
Meanwhile, decreased ruminal $\mathrm{pH}$ together with increased osmotic pressure can damage the epithelial cell integrity and tight junction (Steele et al., 2010), and more LPS will translocate into the blood. On the other hand, in practical dairy production dairy cattle are frequently subjected to mastitis or metritis, under which conditions LPS in the blood and the mammary gland increased dramatically (Eckel and Ametaj, 2016). It was reported that the plasma LPS concentrations displayed a large variation ranging from 0.05 to $86 \mathrm{ng} / \mathrm{mL}$ under various physiological and health conditions in dairy cows (Bilal et al., 2016; Dong et al., 2014; Magata et al., 2017; Khafipour et al., 2009).

Previous studies proved that the presence of LPS in the mammary gland reduced the lactation performance in dairy cows, and the treatment of bMECs with LPS resulted in decreased expression of genes related to milk protein and milk fat synthesis (Chen et al., 2019; Zhang et al., 2019; Zhou et al., 2014). According to these studies, there are several causes for the impaired lactation. The LPSinduced systemic immune response competes with milk component synthesis for substrate supplies, resulting in repartition of milk component precursors away from milk secretion (Zhou et al., 2014). LPS inhibits the activity of key enzymes in milk fat synthesis (Khovidhunki et al., 2004), and even alters lipid and amino acid metabolic pathways through LPS induced DNA methylation. However, few studies have focus on the LPS provoked oxidative DNA damages in bMECs, which could induce cell dysfunction and apoptosis. Thus, the aim of this experiment was to investigate the effects of LPS on the oxidative stress and oxidative DNA damage in bMECs. In the present study, the LPS doses were designed to cover a wild range of plasma LPS concentrations in dairy cows under various health conditions.

\section{MATERIALS AND METHODS}

\section{Cell culture and treatments}

The bovine mammary epithelial cell line (MAC-T) used in this experiment was kindly provided by Professors Jianxin Liu and Hongyun Liu at the Institute of Dairy Science, Zhejiang University, China. The cells were cultured in DMEM/F12 medium (90ml, Gibco, Grand Island, NY, USA) supplemented with feta bovine serum (10ml, Gibco, Grand Island, NY, USA) and penicillinstreptomycin solution ( $1 \mathrm{ml}$, Hyclone, Logan, UT, USA) at $37^{\circ} \mathrm{C}$ in a $\mathrm{CO}_{2}$ incubator (Thermo Fisher Scientific, Waltham, MA, USA).

MAC-T cells were firstly seeded into the culture medium without LPS until $60 \%$ confluence, and then were treated with LPS (Escherichia coli O111:B4, Sigma, Saint Louis, MO, USA) for $48 \mathrm{~h}$ at the concentrations of 0
(Control), $0.1,0.5,2.5,12.5$, and $100 \mathrm{ng} / \mathrm{mL}$, respectively. Culture medium was replaced every $24 \mathrm{~h}$. The cells were harvested at the end of the treatment for further analysis.

\section{Cell viability assay}

Cell viability assay was carried out using the cell counting kit-8 (CCK-8) (Dojindo, Kumamoto, Japan). Based on the instruction of manufacture, $1 \times 10^{4} / \mathrm{mL}$ MAC-T cells were seeded into 96-well culture plates with $100 \mu \mathrm{L}$ per well, and wells without cells were set as blanks and incubated with the same culture medium. After $48 \mathrm{~h}$ incubation, cells and blanks were added with $10 \mu \mathrm{L}$ of CCK-8 into each well, and incubated for another $2 \mathrm{~h}$ before measuring the optical density (OD) at $450 \mathrm{~nm}$ using a microplate reader (Bio-Rad, $\mathrm{xMark}^{\mathrm{TM}}$, USA).

\section{ROS detection}

The production of cellular ROS was measured with ROS detection kits using the chemical fluorescence method (Jiancheng Bioengineering Institute, Nanjing, China). Briefly, $2 \times 10^{5} / \mathrm{mL}$ MAC-T cells were seeded into 6-well plates, and incubated for $48 \mathrm{~h}$ with different LPS treatments. Thereafter, culture medium was replaced with phosphate-buffered saline (PBS) containing $10 \mu \mathrm{M}$ 2,7-dichlorofuorescin diacetate (DCFH-DA), and cells were incubated for another $30 \mathrm{~min}$. Then cells were resuspended in $500 \mathrm{~mL}$ PBS, and cellular fluorescence was detected with a flow cytometer (BD Biosciences, SanDiego, CA, USA) using the fluorescein isothiocyanate (FITC) detection method (excitation and emission wavelength at 488 and $525 \mathrm{~nm}$, respectively). The data analysis was performed using the FlowJo software.

\section{Assay for oxidative damage markers and antioxidant activity}

MAC-T cells were seeded at $2 \times 10^{5} / \mathrm{mL}$ in 6 -well plates, and treated with different LPS levels for $48 \mathrm{~h}$. After incubation, cells were washed twice with PBS, and digested with $0.25 \%$ trypsin/EDTA (Gibco, Grand Island, USA). Harvested cells were then disrupted ultrasonically on ice, and centrifuged at $2500 \mathrm{~g}$ for $5 \mathrm{~min}$ at $4^{\circ} \mathrm{C}$. The supernatant was collected and stored at $-20^{\circ} \mathrm{C}$ for oxidative damage markers and antioxidant activity analyses. The contents of malondialdehyde (MDA), protein carbonyl (PC), 8-hydroxy-2'-deoxyguanosine (8-OHdG), and the activities of Glutathione peroxidase (GSH-Px), catalase (CAT), superoxide dismutase (SOD), and total antioxidant capacity (T-AOC) were determined using ELISA kits (Mlbio, Shanghai, China) following the manufacturer's instructions. Cellular protein concentrations were also measured using bicinchoninic acid (BCA) protein assay kit (Sangon Biotech, Shanghai, China) to normalize the above data. 
$R N A$ isolation, $c D N A$ synthesis, and quantitative real-time $P C R(q P C R)$

MAC-T cells in 6-well plates were harvested after treatment, and total RNA was extracted using TRIzol reagent (Invitrogen, Carlsbad, CA, USA) according to the manufacturer's protocols. The concentration and purity of RNA were measured using a spectrophotometer (Implen, Munich, Germany). Total RNA $(1 \mu \mathrm{g})$ was prepared for reverse transcription process, and cDNA synthesis was performed using the iScript cDNA synthesis kit (Bio-Rad, Hercules, CA, USA). The incubation program consisted of $25^{\circ} \mathrm{C}$ for $5 \mathrm{~min}, 46^{\circ} \mathrm{C}$ for $20 \mathrm{~min}$, and $95^{\circ} \mathrm{C}$ for $1 \mathrm{~min}$. The reverse transcription product was used as cDNA template in $\mathrm{qPCR}$ reaction, and the reaction was conducted in BIORAD CFX96 Real-Time System (Bio-Rad, Hercules, CA, USA) using the Ssofast EvaGreen Supermix kit (Bio-Rad, Hercules, CA, USA). The amplification and quantification were performed with the followed cycling conditions: pre-incubation at $95^{\circ} \mathrm{C}$ for $30 \mathrm{sec}, 40$ cycles of denaturation at $95{ }^{\circ} \mathrm{C}$ for $5 \mathrm{sec}$, and annealing at $60^{\circ} \mathrm{C}$ for $5 \mathrm{sec}$. Melting curves were analyzed to ensure the specific amplification, and relative mRNA expression levels were calculated using the $2^{-\Delta \Delta \mathrm{CT}}$ method. Primers of antioxidant genes and DNA repair genes were designed using Primer Premier 5.0 software (Table I), and synthesized by BGI Co., Ltd (Shenzhen, China). Antioxidant genes include hemeoxygenase 1 (HO-1), SOD, thioredoxin reductase 1
(TXNRD1), NADPH-quinone oxidoreductase 1 (NQO1), and cysteine uptake transporter (XCT), and the DNA repair genes are Fanconi Anemia complementation group D2 protein (FANCD2), and Fanconi Anemia complementation group L (FANCL). The glyceraldehyde3-phosphate dehydrogenase gene (GAPDH) was used as a housekeeping gene.

\section{Western blot analysis}

MAC-T cells in 6-well plates were harvested after treatment, and the total cellular protein was extracted using the Tissue or Cell Total Protein Extraction Kit (Sangon Biotech, Shanghai, China) for the detection of phosphorylated histone $2 \mathrm{AX}(\gamma \mathrm{H} 2 \mathrm{AX})$ expression, which is a sensitive marker of DNA damage. Total protein concentrations were measured using the BCA protein assay kit, and $20 \mu \mathrm{g}$ protein was separated by SDS-PAGE (SurePAGE ${ }^{\mathrm{TM}}$, Bis-Tris, Genscript, Nanjing, China) at $140 \mathrm{~V}$ for $45 \mathrm{~min}$ and electrophoretically transferred to polyvinylidene fluoride (PVDF) membranes (GE Healthcare, Wasukesha, WI, USA). Membranes were blocked for $1 \mathrm{~h}$ with 5\% skim milk buffer (BioFroxx, $\mathrm{KG}$, Germany), and then incubated overnight at $4{ }^{\circ} \mathrm{C}$ with primary antibody against $\gamma \mathrm{H} 2 \mathrm{AX}$ (anti-pSer ${ }^{139}-\mathrm{H} 2 \mathrm{AX}$, Enzo Life Sciences International, Plymouth, PA, USA) or GAPDH (Proteintech, Wuhan, China). Subsequently, membranes were washed 3 times with TBST (APPLYGEN,

Table I. Primer sequences used for quantitative real-time PCR.

\begin{tabular}{|c|c|c|c|}
\hline Gene & Primer sequence & Product size (bp) & Gene Bank association no. \\
\hline \multirow[t]{2}{*}{$\mathrm{HO}-1$} & F: GGCAGCAAGGTGCAAGA & 221 & NM_001014912.1 \\
\hline & R: GAAGGAAGCCAGCCAAGAG & & \\
\hline \multirow[t]{2}{*}{ SOD } & F: GAGGCAAAGGGAGATACAGTC & 197 & NM_174615.2 \\
\hline & R: GTCACATTGCCCAGGTCTC & & \\
\hline \multirow[t]{2}{*}{ TXNRD1 } & F: GTGTTCACGACTCTGTCGGT & 240 & NM_174625.3 \\
\hline & R: CTGCCTTCCACGAATCACCT & & \\
\hline \multirow[t]{2}{*}{ NQO-1 } & F: GGTGCTCATAGGGGAGTTCG & 235 & NM_001034535.1 \\
\hline & R: GGGAGTGTGCCCAATGCTAT & & \\
\hline \multirow[t]{2}{*}{$\mathrm{XCT}$} & F: GATACAAACGCCCAGATATGC & 136 & XM_002694373.2 \\
\hline & R: ATGATGAAGCCAATCCCTGTA & & \\
\hline \multirow[t]{2}{*}{ FANCD2 } & F: AGTGAACACGGCAGAACAGT & 152 & NM_001192429.1 \\
\hline & R: CAGTCCCACCTACGAAGGAAA & & \\
\hline \multirow[t]{2}{*}{ FANCL } & F: ACCCCTGGGAATTAGGCTGA & 183 & NM_001076332.2 \\
\hline & R: TGATCAGGAATGGCACCATCA & & \\
\hline GAPDH & F: GGGTCATCATCTCTGCACCT & 177 & NM_001034034.2 \\
\hline
\end{tabular}

HO-1, hemeoxygenase 1; SOD, superoxide dismutase; TXNRD1, thioredoxin reductase 1; NQO-1, NADPH-quinone oxidoreductase 1; XCT, cysteine uptake transporter; FANCD2, Fanconi Anemia complementation group D2 protein; FANCL, Fanconi Anemia complementation group L; GAPDH, glyceraldehyde-3-phosphate dehydrogenase. 
Beijing, China) and incubated at room temperature for 1 $\mathrm{h}$ with secondary antibody (HRP-conjugated Affinipure Goat Anti-Mouse IgG, Proteintech, Wuhan, China). Then membranes were washed 3 times with TBST, and immunoreactive protein bands on the membranes were developed with the Clarity Western ECL Substrate Reagent (Bio-Rad, Hercules, CA, USA). Finally, the membranes were visualized using the ChemiDoc ${ }^{\mathrm{TM}}$ MP System (Bio-Rad, Herculers, CA, USA), and the band density was measured using Image Lab 6.0.1 software (Bio-rad, Herculers, CA, USA).

\section{Statistical analysis}

Data were expressed as the means \pm standard error (SE, $\mathrm{n}=6$ ), and statistical analysis was performed using SPSS 19.0 (IBM Inc., Armonk, NY, USA) and GraphPad PRISM 5.0 (Graph Pad Software, La Jolla, CA, USA). Probability value $(P$-value $)$ of $<0.05$ was considered statistically significant. One-way analysis of variance (ANOVA) followed with Duncan's multiple comparison was used to determine the statistical significance among variables of different treatments. The statistical correlation was performed using GraphPad PRISM 5.0, and $P$-value and $\mathrm{R}^{2}$ were computed to evaluate the goodness of fit.

\section{RESULTS}

\section{Cell viability and ROS production}

Treatment of MAC-T cells with different levels of LPS ( 0 to $100 \mathrm{ng} / \mathrm{mL}$ ) resulted in dose-dependent reduction of cell viability (Fig. 1A), and the correlation analysis showed that the cell viability was negatively correlated with LPS concentrations (Fig. 1B). On the contrary, cellular ROS production exhibited a dose-dependent rise under LPS treatments (Fig. 2).
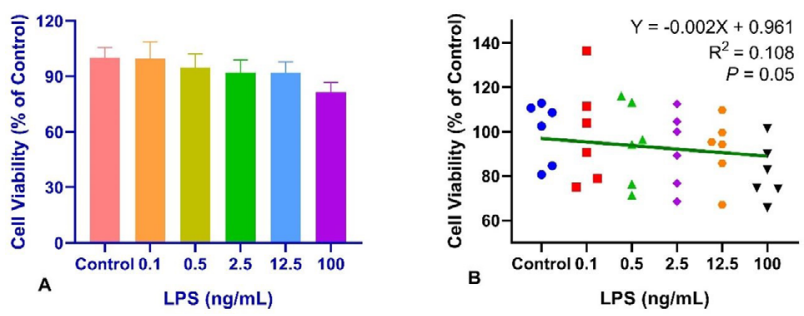

Fig. 1. Effects of different LPS levels on the cell relative viability (A) and correlation analysis between LPS levels and cell viability (B) in MAC-T cells.

\section{Oxidative damage markers' concentrations}

As shown in Figure 3 (A, C, and E), treatment with LPS at $100 \mathrm{ng} / \mathrm{mL}$ significantly increased $(P<0.05)$ the concentrations of PC and 8-OHdG, while no significant effects of LPS on the concentration of MDA were observed. There existed a significant linear correlation between LPS levels and $\mathrm{PC}$ and $8-\mathrm{OHdG}$ concentrations (Figs. 3B, D and F).

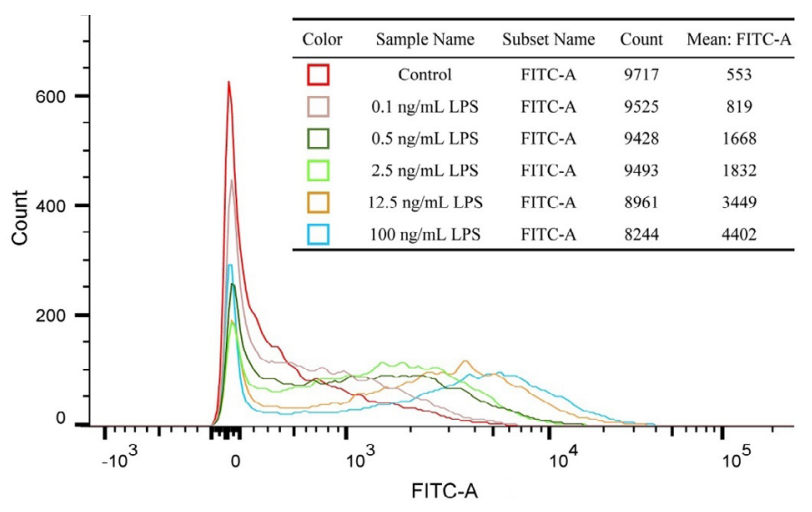

Fig. 2. Effects of different LPS levels on the cellular ROS production in MAC-T cells. The representative flow cytometric results are showed in the histogram, and the line color and its corresponding sample name, total cell count, and mean fluorescence intensity are showed in the upper right table. Mean fluorescein isothiocyanate-A (FITC-A) values represent ROS concentrations.

\section{Activities of antioxidants}

The T-AOC was significantly higher $(P<0.05)$ under treatments from 0.5 to $100 \mathrm{ng} / \mathrm{mL}$ LPS, compared with control and $0.1 \mathrm{ng} / \mathrm{mL}$ LPS treatment (Fig. 4A). The effects of LPS at different levels on the SOD activity displayed an irregular pattern with a higher SOD activity at 0.5 and $2.5 \mathrm{ng} / \mathrm{mL}$ of LPS (Fig. 4B). Meanwhile, LPS had no significant effects on GSH-Px and CAT activities.

\section{Gene expression of antioxidants}

As presented in Figure 5, the relative gene expression of HO-1 in MAC-T cells treated with 12.5 and $100 \mathrm{ng} / \mathrm{mL}$ LPS was significantly upregulated $(P<0.05)$ compared with that in control and treatments with 0.1 and $0.5 \mathrm{ng} / \mathrm{mL}$ LPS. The gene expressions of SOD and NQO-1 at $100 \mathrm{ng} /$ mL LPS were significantly higher $(P<0.05)$ than at 12.5 $\mathrm{ng} / \mathrm{mL}$ LPS. Treatments with LPS did not affect relative gene expression of XCT and TXNRD1.

\section{DNA repair gene expression}

Treatment with $100 \mathrm{ng} / \mathrm{mL}$ LPS significantly increased $(P<0.05)$ the relative gene expression of FANCD2 compared to control and other treatments (Figure 6A). Treatments with $0.1,0.5$ and $2.5 \mathrm{ng} / \mathrm{mL}$ LPS had significantly increased $(P<0.05)$ the relative gene expression of FANCD2 compared with the 12.5 
ng/mL LPS treatment. Treatment with $100 \mathrm{ng} / \mathrm{mL}$ LPS significantly upregulated $(P<0.05)$ the relative gene expression of FANCL compare with control and other treatments (Fig. 6B).
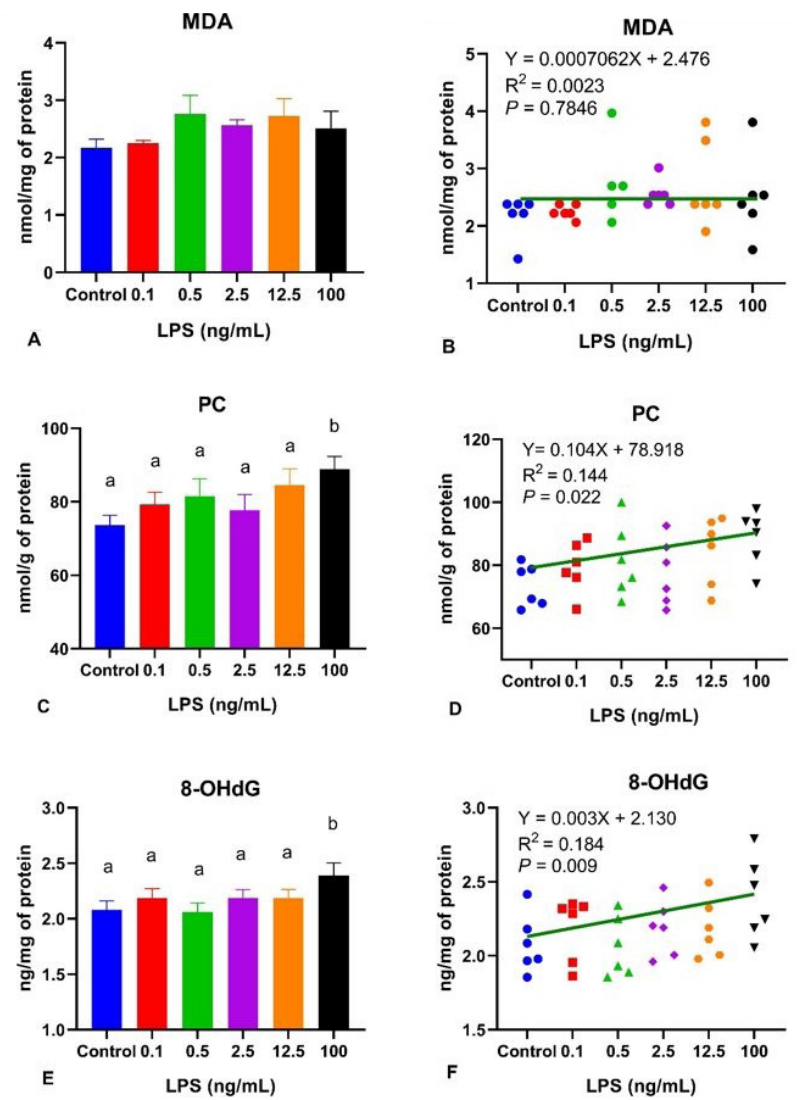

Fig. 3. Effects of different LPS levels on oxidative damage markers' concentrations (A, C, and E), and the correlation between LPS and markers' levels (B, D, and F) in MAC-T cells. Columns without a common lowercase letter (a, b) indicate significant difference among treatments $(P<$ 0.05). MDA, malondialdehyde; PC, protein carbonyl; 8-OHdG, 8-hydroxy-2'-deoxyguanosine.

\section{DNA damage marker protein expression}

In MAC-T cells, $\gamma \mathrm{H} 2 \mathrm{AX}$ protein expression was upregulated with increasing concentrations of LPS from 0 to $12.5 \mathrm{ng} / \mathrm{mL}$, but declined when LPS level reached 100 ng/mL (Fig. 7).

\section{DISCUSSION}

In order to evaluate the LPS induced oxidative stress and damage to major biomolecules in bMECs, we measured the cell viability, ROS production and oxidative damage markers in the present study. Although cell apoptosis plays an important role in maintaining homeostasis in organisms, excessive apoptosis stimulated by extracellular agents results in increased cell death and reduced cell viability. ROS can elicit protein misfolding and the sustained oxidative stress can initiate apoptotic cascades by activating plasma membrane death receptors (Li et al., 2019). Previous studies had investigated cell apoptosis and viability in bMECs with different prooxidants (Jin et al., 2016; Li et al., 2019). With regard to LPS, cells treated with relatively high levels (1000 ng/mL or higher) exhibited reduction in viability and upregulated cell apoptosis-associated regulatory proteins, whereas relatively low concentrations showed no significant effects. In our study, the correlation analysis demonstrated negatively linear relationship between LPS concentrations and cell viability. Together with multi-fold increases in ROS production with increasing LPS levels, it can be seen that ROS induced cell apoptosis in a dosedepend manner, and the declined cell viability further attested to the occurrence of oxidative stress. Moreover, LPS treatments increased the yield of PC and 8-OHdG, which are common products of protein peroxidation and DNA damage (Simm and Brömme, 2005), indicating protein and DNA damage occurred during the LPSinduced oxidative stress.
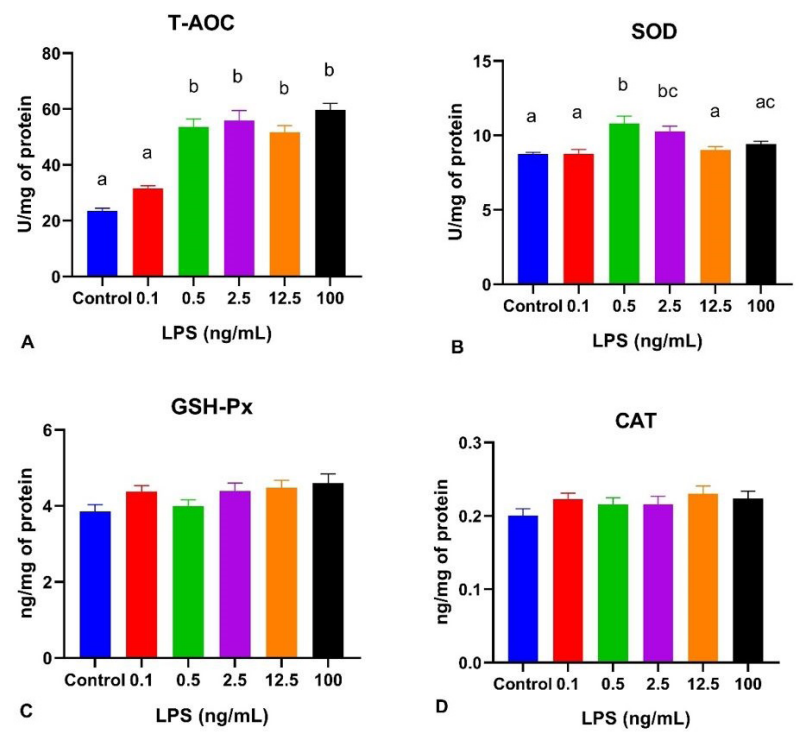

Fig. 4. Effects of different LPS levels on the activities of antioxidants in MAC-T cells. Columns without a common lowercase letter $(\mathrm{a}, \mathrm{b}, \mathrm{c})$ indicate significant difference among treatments $(P<0.05)$. T-AOC, total antioxidant capacity; GSH-Px, glutathione peroxidase; CAT, catalase; SOD, superoxide dismutase. 

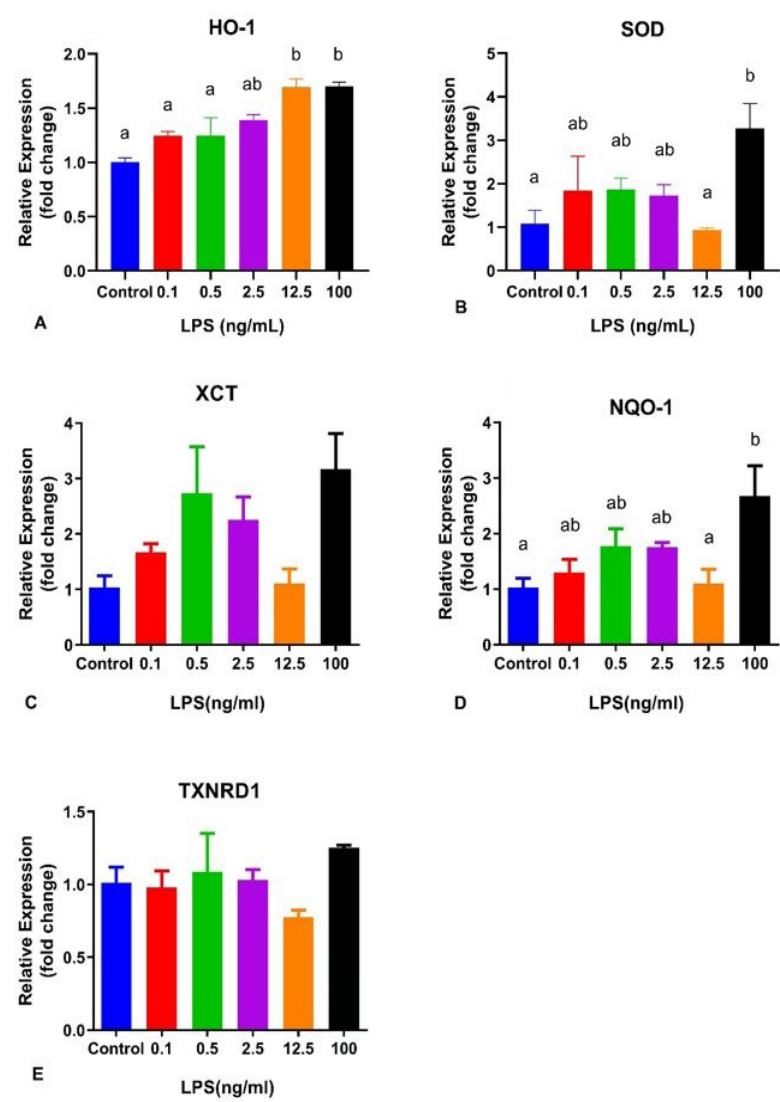

Fig. 5. Effects of different LPS levels on the relatively expression of antioxidative genes in MAC-T cells. Columns without a common lowercase letter $(\mathrm{a}, \mathrm{b})$ indicate significant difference among treatments $(P$ $<0.05$ ). HO-1, hemeoxygenase 1; SOD, superoxide dismutase; XCT, cysteine uptake transporter; NQO-1, NADPH-quinone oxidoreductase; TXNRD1, thioredoxin reductase 1 .
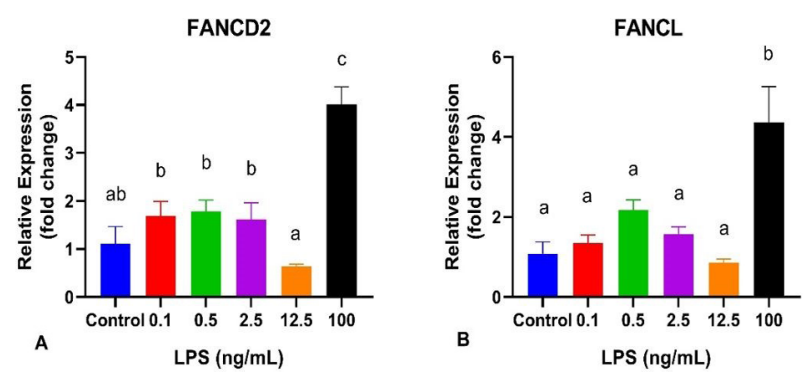

Fig. 6. Effects of LPS on the relatively expression of DNA repair genes in MAC-T cells. Columns without a common lowercase letter $(\mathrm{a}, \mathrm{b}, \mathrm{c})$ indicate significant difference among treatments $(P<0.05)$. FANCD2, Fanconi Anemia complementation group D2 protein; FANCL, Fanconi Anemia complementation group L.
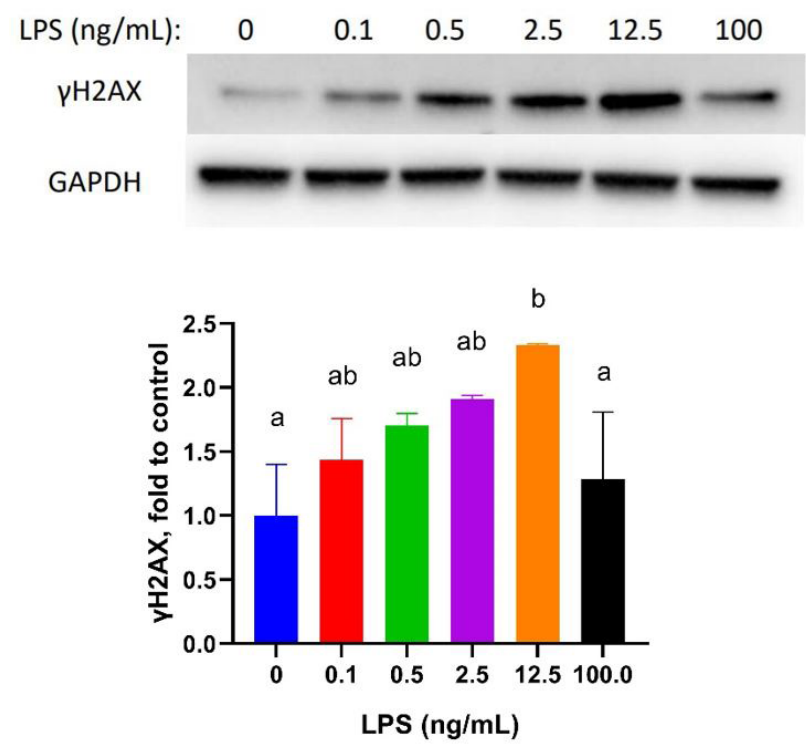

Fig. 7. Effects of different LPS levels on $\gamma \mathrm{H} 2 \mathrm{AX}$ protein expression in MAC-T cells. Columns without a common lowercase letter $(\mathrm{a}, \mathrm{b})$ indicate significant difference among treatments $(P<0.05) . \gamma \mathrm{H} 2 \mathrm{AX}$, phosphorylated histone $2 \mathrm{AX}$.

we also analyzed the activity and gene expression of representative antioxidants under the LPS treatments. The activity of SOD, GSH-Px and CAT, and T-AOC is important indicator of the antioxidant capacity in organisms. SOD and CAT play crucial roles in reducing high level of intracellular superoxide radicals by catalyzing their catabolism into hydrogen peroxide and water, while GSH-Px degrades reactive oxygen intermediates to prevent them from interacting with critical cellular components, such as the phospholipids of bio-membranes, nucleic acids, and proteins (Hsu et al., 2006; Moriya et al., 2000). Under SARA, increased SOD activity and reduced T-AOC, GSH-Px, and CAT activity were found in both the liver and plasma of dairy cows (Abaker et al., 2017). When bMECs were treated with $1000 \mathrm{ng} / \mathrm{mL}$ LPS, cellular levels of SOD, T-AOC, GSH-Px, and CAT significantly declined (Li et al., 2019; Zhang et al., 2019). HO-1, NQO-1, XCT and TXNRD1 are genes mediated by nuclear factor erythroid 2-related factor 2 (Nrf2), which is a crucial transcription factor in regulating the expression of antioxidant/detoxifying enzymes and protecting cells against oxidative-induced cytotoxicity (Cho et al., 2005; Jin et al., 2016). HO-1 and NQO-1 are major enzymes with the abilities to enhance antioxidant activity (Liang et al., 2013). As an important antioxidant selenoprotein in bovine, Txnrdl can reduce oxidized cysteine groups on proteins using the redox-active center together with 
NADPH (Sordillo and Aitken, 2009). XCT has the capability to regulate cell defense in maintaining redox homeostasis (Ma, 2013). Previous research evaluated HO- 1 expression in different organs of mice after 4 and 24 $\mathrm{h}$ LPS administration, and found LPS markedly induced HO-1 mRNA expression in the liver, kidneys, and lungs (Wiesel et al., 2000). On the other hand, an in vitro study using MECs detected decreased HO-1 and Nrf2 gene expression after $12 \mathrm{~h}$ LPS stimulation (Yu et al., 2017). When continuous monitoring the gene expression in MAC-T cells within $24 \mathrm{~h}$, upregulated gene expression of HO-1, XCT and Txnrd1 were observed in the first 4 $\mathrm{h}$ and then declined with persistent $\mathrm{H}_{2} \mathrm{O}_{2}$ inducement (Jin et al., 2016). In our current study, the antioxidative capability of MAC-T cell was higher under LPS treatments with increased activity of T-AOC and SOD and mRNA expression of antioxidants genes including HO-1, NQO-1 and SOD. In contrast with previous results, we speculated that the activation of antioxidative defense and oxidative damage of cellular biomolecular synchronized during the first stage of oxidative stress. However, as LPS levels increased, excessive oxidative damage to cellular biomolecules resulted in impaired antioxidative defense.

Furthermore, we explored the relationship between DNA damage and DNA repair function under LPS treatments. Fanconi anemia (FA) is a recessively inherited genetic disorder associated with severe bone marrow failure and increasing cancer susceptibility, characterized by chromosomal abnormalities and hypersensitivity to DNA crosslinking agents (Sarren et al., 2012). Among fifteen identified FA genes whose protein products shared a common pathway (the FA pathway), FANCD2 and FANCL are the downstream targets when the FA pathway is activated upon DNA damage (Kitao and Takata, 2011; Moldovan and D'Andrea, 2009). FANCD2 and FANCL were proved to guard genome stability by cooperating with many known repair proteins and pathways including ataxia telangiectasia mutated (ATM) pathway in nearly all phases of DNA damage response, including damagesensing, signal transduction, and execution of DNA repair. In stressed cells, FANCD2 can also facilitate the initiation of ATM signaling upstream via its involvement in the phosphorylation of H2AX which is a substrate of ATM (Nepal et al., 2017). As a histone protein variant, phosphorylation of $\mathrm{H} 2 \mathrm{AX}$ is one of the first processes initiated by DNA damage, especially in double strand breaks (Redon et al., 2002). Previous studies detected increased protein expression of $\gamma \mathrm{H} 2 \mathrm{AX}$ under short-term oxidative stress induced by $\mathrm{H}_{2} \mathrm{O}_{2}$ or cortisol (Chen et al., 2005; Flaherty et al., 2017). In our current study, $\gamma \mathrm{H} 2 \mathrm{AX}$ protein expression gradually increased as LPS levels increased from 0 to $12.5 \mathrm{ng} / \mathrm{mL}$, but significantly declined when LPS level reached $100 \mathrm{ng} / \mathrm{mL}$. The gene expression of both FANCD2 and FANCL was upregulated about 4 folds at $100 \mathrm{ng} / \mathrm{mL}$ LPS, whereas LPS at lower doses had minor effects on their gene expression. These results suggest that as a sensitive biomarker of DNA damage, phosphorylation of $\mathrm{H} 2 \mathrm{AX}$ occurred at the early stage of oxidative stress. The rise of $\gamma \mathrm{H} 2 \mathrm{AX}$ due to increased DNA damage initiated DNA repair pathways as a feedback mechanism, resulting in alleviation of DNA damage.

\section{CONCLUSION}

Overall, LPS induced oxidative stress in a dosedependent manner in bMECs. Meanwhile, LPS stimulated the antioxidative defense which was enhanced with increasing LPS levels. However, the enhanced antioxidative defense could not offset the LPS induced damage to cellular biomolecules including DNA in bMECs.

\section{ACKNOWLEDGEMENTS}

This study was sponsored by natural science foundation of Chongqing, China (Grant number: cstc2018jcyjA0834), and the National Natural Science Foundation of China (Grant number: 31672448).

\section{Statement of conflict of interest}

The authors have declared no conflict of interest.

\section{REFERENCES}

Abaker, J.A., Xu, T.L., Jin, D., Chang, G.J., Zhang, K. and Shen, X.Z., 2017. Lipopolysaccharide derived from the digestive tract provokes oxidative stress in the liver of dairy cows fed a high-grain diet. $J$. Dairy Sci., 100: 666-678. https://doi.org/10.3168/ jds.2016-10871

Altieri, F., Grillo, C., Maceroni, M. and Chichiarelli, S., 2008. DNA damage and repair: from molecular mechanisms to health implications. Antioxid. Redox Signa., 10: 891-937. https://doi.org/10.1089/ ars.2007.1830

Bilal, M.S., Abaker, J.A., Aabdin, Z., Xu, T.L., Dai, H.Y., Zhang, K., Liu, XX. and Shen, X.Z., 2016. Lipopolysaccharide derived from the digestive tract triggers an inflammatory response in the uterus of mid-lactating dairy cows during SARA. BMC Vet. Res., 12: 284-290. https://doi.org/10.1186/s12917016-0907-1

Chen, J.H., Ozanne, S.E. and Hales, C.N., 2005. Heterogeneity in premature senescence by oxidative stress correlates with differential DNA 
damage during the cell cycle. DNA Repair, 4: 11401148. https://doi.org/10.1016/j.dnarep.2005.06.003

Chen, J., Wu, Y., Sun, Y., Dong X., Wang, Z., Zhang, Z., Xiao, Y. and Dong, Z., 2019. Bacterial lipopolysaccharide induced alterations of genomewide DNA methylation and promoter methylation of lactation-related genes in bovine mammary epithelial cells. Toxins, 11: 298-312. https://doi. org/10.3390/toxins 11050298

Cho, H.Y., Reddy, S.P., Debiase, A., Yamamoto, M. and Kleeberger, S.R., 2005. Gene expression profiling of Nrf2-mediated protection against oxidative injury. Free Radic. Biol. Med., 38: 325-343. https:// doi.org/10.1016/j.freeradbiomed.2004.10.013

Dong, G., Qiu, M., Ao, C., Zhou, J., Erdene, K., Wang, X., Zhang, Z. and Yang, Y., 2014. Feeding a highconcentrate corn straw diet induced epigenetic alterations in the mammary tissue of dairy cows. PLoS One, 9: e107659. https://doi.org/10.1371/ journal.pone.0107659

Dröge, W., 2002. Free radicals in the radicals in the physiological control of cell function. Physiol. Rev., 82: 47-95. https://doi.org/10.1152/ physrev.00018.2001

Eckel, E.F. and Ametaj, B.N., 2016. Invited review: role of bacterial endotoxins in the etiopathogenesis of periparturient diseases of transition dairy cows. $J$. Dairy Sci., 99: 5967-5990. https://doi.org/10.3168/ jds.2015-10727

Flaherty, R.L., Owen, M., Fagan-Murphy, A., Intabli, H., Healy, D., Patel, A., Allen, M.C., Patel, B.A., Flint, M.S., 2017. Glucocorticoids induced production of reactive oxygen species/reactive nitrogen species and DNA damage through an iNOS mediated pathway in breast cancer. Breast Cancer Res., 19: 35-47. https://doi.org/10.1186/s13058-017-0823-8

Gressley, T.F., Hall, M.B. and Aremtano, L.E., 2011. Ruminant nutrition symposium: Productivity, digestion, and health responses to hindgut acidosis in ruminants. J. Anim. Sci., 89: 1120-1130. https:// doi.org/10.2527/jas.2010-3460

Hsu, D.Z., Li, Y.H., Chu, P.Y., Chien, S.P., Chuang, Y.C. and Li, M.Y., 2006. Attenuation of endotoxininduced oxidative stress and multiple organ injury by 3,4-methylenedioxyphenol in rats. Shock, 25: 300-305. https://doi.org/10.1097/01. shk.0000194719.82845.39

Iwasaki, A. and Medzhitov, R., 2004. Toll-like receptor control of the adaptive immune responses. Nat. Immunol., 5: 987-995. https://doi.org/10.1038/ nil112

Jin, D., Chang, G., Zhang, K., Guo, J., Xu, T. and Shen,
X., 2016. Rumen-derived lipopolysaccharide enhances the expression of lingual antimicrobial peptide in mammary glands of dairy cows fed a high-concentrate diet. BMC Vet. Res., 12: 128-137. https://doi.org/10.1186/s12917-016-0755-Z

Jin, X., Wang, K., Liu, H., Hu, F., Zhao, F. and Liu, J., 2016. Protection of bovine mammary epithelial cells from hydrogen peroxide-induced oxidative cell damage by resveratrol. Oxid. Med. Cell Longev., 2016: 2572175. https://doi. org/10.1155/2016/2572175

Khafipour, E., Krause, D.O. and Plaizier, J.C., 2009. A grain-based subacute ruminal acidosis challenge causes translocation of lipopolysaccharide and triggers inflammation. J. Dairy Sci., 92: 10601070. https://doi.org/10.3168/jds.2008-1389

Khovidhunkit, W., Kim, MS., Memon, R.A., Shigenaga, J.K., Moser, A.H., Feingold, K.R. and Grunfeld, C., 2004. Effects of infection and inflammation on lipid and lipoprotein metabolism: Mechanisms and consequences to the host. J. Lipid Res., 45: 11691196. https://doi.org/10.1194/jlr.R300019-JLR200

Kitao, H., and Takata, M., 2011. Fanconi anemia: a disorder defective in the DNA damage response. Int. J. Hematol., 93: 417-424. https://doi.org/10.1007/ s12185-011-0777-z

Li, L., Wang, H., Nie, X., Jiang, W. and Zhang, Y., 2019. Sodium butyrate ameliorates lipopolysaccharideinduced cow mammary epithelial cells from oxidative stress damage and apoptosis. J. Cell Biochem., 120: 2370-2381. https://doi.org/10.1002/ jcb. 27565

Liang, L., Gao, C., Luo, M., Wang, W., Zhao, C., Zu, Y., Efferth, T. and Fu, Y., 2013. Dihydroquercetin (DHQ) induced HO-1 and NQO-1 expression against oxidative stress through the Nrf2-dependent antioxidant pathway. J. Agric. Fd. Chem., 61: 27552761. https://doi.org/10.1021/jf304768p

Ma, Q., 2013. Role of Nrf2 in oxidative stress and toxicity. Annu. Rev. Pharmacol., 53: 401-426. https://doi. org/10.1146/annurev-pharmtox-011112-140320

Magata, F., Morino, I., Teramura, M., Tsunoda, E., Kawashima, C., Haneda, S., Miyamoto, A., Kida, K. and Shimizu, Y., 2017. Impact of metritis on the generation of reactive oxygen species by circulation phagocytes and plasma lipopolysaccharide concentration in peripartum dairy cows. Anim. Sci. J., 88: 248-253. https://doi.org/10.1111/asj.12642

Moldovan, G.L. and D'Andrea, A.D., 2009. How the Fanconi anemia pathway guards the genome. Annu. Rev. Genet., 43: 223-249. https://doi.org/10.1146/ annurev-genet-102108-134222 
Moriya, S., Yokoyama, H., Fukuda, M., Okamura, Y., Kamegaya, Y., Mizukami, T., Ohgo, H. and Ishii, H., 2000. Glutathione depletion enhances the formation of superoxide anion released into hepatic sinusoids after lipopolysaccharide challenge. Alcohol. clin. exp. Res., 24: 59S-63S. https://doi. org/10.1111/j.1530-0277.2000.tb00014.x

Nepal, M., Che, R., Ma, C., Zhang, J. and Fei, P., 2017. FANCD2 and DNA damage. Int. J. mol. Sci., 18: 1804-1812. https://doi.org/10.3390/ijms18081804

Porcherie, A., Cunha, P., Trotereau, A., Roussel, P., Gilbert, F.B., Rainard, P. and Germon, P., 2012. Repertoire of Escherichia coli agonists sensed by innate immunity receptors of the bovine udder and mammary epithelial cells. Vet. Res., 43: 14-21. https://doi.org/10.1186/1297-9716-43-14

Redon, C., Pilch, D., Rogakou, E., Sedelnikova, O., Newrock, K. and Bonner, W., 2002. Histone H2A variants $\mathrm{H} 2 \mathrm{AX}$ and H2AZ. Curr. Opin. Genet. Dev., 12: 162-169. https://doi.org/10.1016/S0959437X(02)00282-4

Sareen, A., Chaudhury, I., Adams, N. and Sobeck, A., 2012. Fanconi anemia proteins FANCD2 and FANCL exhibit different DNA damage responses during S-phase. Nucl. Acids Res., 40: 8425-8439. https://doi.org/10.1093/nar/gks638

Shukla, P.C., Singh, K.K., Yanagawa, B., Teoh, H. and Verma, S., 2010. DNA damage repair and vardiovascular diseases. Can. J. Cardiol., 26: 13A-16A. https://doi.org/10.1016/S0828$282 \mathrm{X}(10) 71055-2$

Simm, A. and Brömme, H.J., 2005. Reactive oxygen species (ROS) and aging: Do we need them, can we measure them, should we block them? Signal Transduct., 5: 115-125. https://doi.org/10.1002/ sita.200400053

Sordillo, L.M. and Aitken, S.L., 2009. Impact of oxidative stress on the health and immune function of dairy cattle. Vet. Immunol. Immunop., 128:104109. https://doi.org/10.1016/j.vetimm.2008.10.305

Steele, M.A., Croom, J., Kahler, M., Alzahal, O. and Mcbride, B.W., 2010. Bovine rumen epithelium undergoes rapid structural adaptations during graininduced subacute ruminal acidosis. Am. J. PhysiolReg. I., 300: R1515-1523. https://doi.org/10.1152/ ajpregu.00120.2010

Wiesel, P., Patel, A.P., Difonzo, N., Marria, P.B., Sim, C.U. Pellacani, A., Maenura, K., LeBlanc, B.W., Marino, K., Doerschuk, C.M., Yet, S.F., Lee, M.E. and Perrella, M.A., 2000. Endotoxin-induced mortality is related to increased oxidative stress and end-organ dysfunction, not refractory hypotension, in heme oxygenase-1-deficient mice. Circulation, 102: 3015-3022. https://doi.org/10.1161/01. CIR.102.24.3015

Yu, G.M., Kubota, H., Okita, M. and Maeda, T., 2017. The anti-inflammatory and antioxidant effects of melatonin on LPS-stimulated bovine mammary epithelial cells. PLoS One, 12: e0178525. https:// doi.org/10.1371/journal.pone.0178525

Zhang, B., Guo, Y., Yan, S., Guo, X., Zhao, Y. and Shi, B., 2019. The protective effect of selenium on the lipopolysaccharide-induced oxidative stress and depressed gene expression related to milk protein synthesis in bovine mammary epithelial cells. Biol. Trace Elem. Res., https://doi.org/10.1007/s12011019-01961-7

Zhou, J., Dong, G., Ao, C., Zhang, S., Qiu, M., Wang, X., Wu, Y., Erdene, K., Jin, L. Lei, C. and Zhang, Z., 2014. Feeding a high-concentrate corn straw diet increased the release of endotoxin in the rumen and pro-inflammatory cytokines in the mammary gland of dairy cows. BMC Vet. Res., 10: 172-180. https://doi.org/10.1186/s12917-014-0172-0 